\title{
The Automatic Selection of Radial Distortion Models
}

\author{
Rihab K. Hamad \\ Optoelectronics Department/ \\ College of Engineering \\ University of Technology/ Iraq
}

\author{
Baidaa Hamed \\ Physics Science Department/ \\ College of Science \\ Mustansiriyah University/ Iraq
}

\author{
H. A. Hassonny \\ Control and system \\ Engineering Department/ \\ College of Engineering \\ University of Technology/ Iraq
}

\begin{abstract}
Several kinds of distortions exist in imaging systems which in specific circumstances may affect an image's geometry without debilitating quality or diminishing the information existing in the image. The most important type is the radial distortion which represents high distortion accurately. Many lens distortion models exist combined with several variations where different techniques are used to calibrate each distortion model. This paper presents an algorithm to select automatically the best lens distortion model for four lenses of different focal length using different statistical information criterion without sacrificing a significantly lower error. The used method requires a simple chessboard pattern, which observed from different position and calibrated using Zhang method, to compute the complexity of the lens distortion model automatically.
\end{abstract}

The result shows the $6^{\text {th }}$ order radial distortion model is the best model with the minimum error about -0.273 for lens of focal length $30.64 \mathrm{~mm}$ using MDL criteria, while at $4^{\text {th }}$ order the minimum error about -0.177 , and at $2^{\text {nd }}$ order about 0.112 .

\section{Keywords}

Camera Calibration, Radial Distortion, Lenses

\section{INTRODUCTION}

Camera lens distortion is significant in a medium to wide angle lenses. At present many distortion models and executing are available for evaluating camera lens distortion choosing the right model and executing could provide accurate result. The simpler methods which are used by the computer vision community have been developed due to the complexity of the evaluation trials and advances in the use of computers for analytical analysis [1, 2 and 3]. Numerous PC vision calculations critically depended upon the supposition of a linear pinhole camera, especially structure from motion algorithms. Some of the proposed distortion calibration methods consider an automatic distortion model selection method [4, 5 and 6]. There are several kinds of lens distortion but the most effective kind is the radial distortion. Which bends straight lines into circular arcs, and it's important in higher quality cameras that introduce error into 3 dimension reconstruction processes $[7,8]$. Radial distortion may appear as a barrel distortion, which arising usually at short focal lengths, or pincushion distortion, which arising usually at longer focal lengths.

\section{RADIAL DISTORTION}

It's the main kind of lens distortion which formed by defects in lens shape and displays itself only as radial positional error. While the other types of distortion are usually created by indecorous lens and camera gathering, produce both radial and tangential errors in point positions. Radial distortion is a linear motion for the image point radially from or to the image center, due to the fact that objects at several angular spaces from the lens axis suffer many amplifications and its lack in a straight line transmission. It is important to indicate that radial distortion is exceedingly connected with focal length, even if it's not modeled within intrinsic parameters of the camera [9, $10]$.

The following polynomial equation symbolizes the radial distortion [11]:

$$
r f(r)=r\left(1+k_{1} r^{2}+k_{2} r^{4}+. .\right)
$$

Where $k_{1}, k_{2}$ are the distortion coefficients and $r^{2}=x^{2}+y^{2}$. The most commonly radial distortion models that have been used are still in the polynomial form of (1) until recently.

The previous polynomial radial distortion models are used with n-orders act as standards for evaluating the performance of the radial distortion models automatically which will be presented in results section.

\section{DISTORTION MODEL SELECTION}

When several competing models for a given system can represent the distortion, the task of distortion model selection would be good for choosing the finest model. Using the most fitting and instructions model will give both better precision and decreased computational model complexity. The model with more degrees of freedom in most cases will fit the data closer than other less complex models [5, 7]. Sum of common and actual model selection criteria is commonly used in different applications. These criterions shows a good perform in computer vision applications.

In the following criteria the parameters of the equations as follow: $N$ refers to the number of samples, $k$ is the parameters number in the model, and SSE Refers to the sum-square-error (SSE) computed as: $\mathrm{SSE}=\sum_{i} r_{i}{ }^{2}$ Where $r^{2}{ }_{i}=\left\|m_{i}-m_{i}{ }_{i}\right\|$ is the difference between the measured and estimated image points.

\subsection{Akaike Information Criterion (AIC):}

AIC is the first criteria presented in statistics literature for model selection. It has the following form:

$$
\mathrm{AIC}=N \ln (\mathrm{SSE} / N)+2 k
$$

The model that can depict any future information adequately with a similar distribution is correct and chosen by AIC.

In other words, AIC selects the model that reduces the error of another perception. And it can compare very different models [8].

3.2 Bayesian Information Criterion (BIC):

BIC is presented by Schwarz in 1978; the principle of this criterion is as following: 
Choose the model that maximizes the conditional probability data. This data is constrained by some priori information data. The BIC can take different structures depending on the supposed priori data [8]. It has the following form:

$\mathrm{BIC}=N \ln (\mathrm{SSE} / N)+k \log N$

\subsection{Consistent AIC (CAIC):}

Bozdogan presented CAIC in 1987, it is an endeavor to conquer the tendency of the AIC to overestimate the complexity of the model [9]. It has the following form:

$$
\mathrm{CAIC}=N \ln (\mathrm{SSE} / N)+k(\log N+1)
$$

\subsection{Minimum Description Length (MDL):}

MDL is presented by rissanen in 1978, the simplest model that depicts the information adequately will be chosen in MDL [10]. It has the following form:

$$
\mathrm{MDL}=N \ln (\mathrm{SSE} / N)+2 k \log N
$$

the explained model selection criterions are shown in Table 1

Table 1. Model Selection Criterions

\begin{tabular}{|l|l|}
\hline Model selection criterions & Formula \\
\hline AIC & $N \ln (\mathrm{SSE} / N)+2 k$ \\
\hline BIC & $N \ln (\mathrm{SSE} / N)+k \log N$ \\
\hline $\mathrm{CAIC}$ & $N \ln (\mathrm{SSE} / N)+k(\log N+1)$ \\
\hline $\mathrm{MDL}$ & $N \ln (\mathrm{SSE} / N)+2 k \log N$ \\
\hline
\end{tabular}

\section{RESULTS}

The presented algorithm shown in figure (1) consists of two process calibration and model selection process. The calibration was done for the three radial models $\left(2^{\text {nd }}, 4^{\text {th }}\right.$ and $6^{\text {th }}$ order) and four lenses of different focal length $70 \mathrm{~mm}$, $100 \mathrm{~mm}, 150 \mathrm{~mm}$, and $190 \mathrm{~mm}$ using Zhang method. A simple chessboard pattern was observed from different position with resolution of $1830 \times 1330$, and the model plane contained of $8 \times 11=88$ points corner. For each lens five different images were used and calibrated. The equations (2, 3, 4 and 5) of the criteria were applied to select the best model and show the performance of the different radial distortion models. Figure (2) shows one image for each lens.

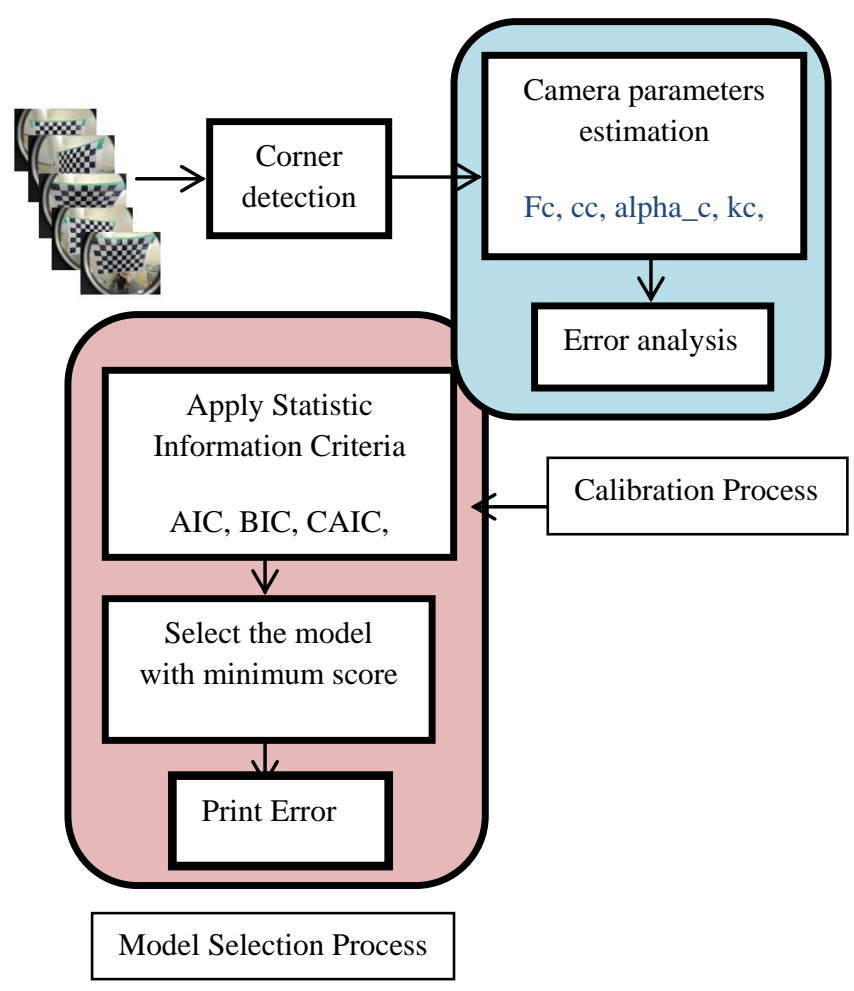

Fig 1. The Presented Algorithm

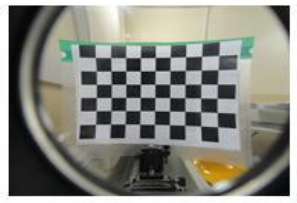

(a)

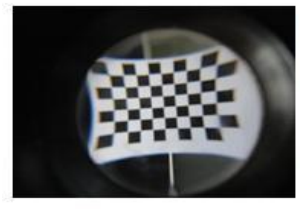

(c)

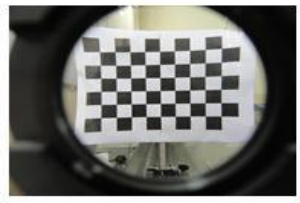

(b)

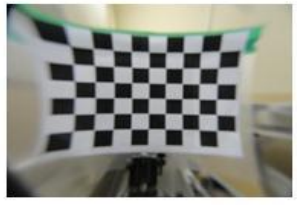

(d)
Fig 2. Images captured with (a) $190 \mathrm{~mm}$, (b) $150 \mathrm{~mm}$, (c) $100 \mathrm{~mm}$, and (d) $70 \mathrm{~mm}$ lens.

Tables $(2,3$, and 4$)$ show the calibration results for $2^{\text {nd }}, 4^{\text {th }}$ and $6^{\text {th }}$ order radial distortion model after optimization for the used lenses.

Table 2. Calibration result after optimization using $2^{\text {nd }}$ order distortion model for Several Lenses

\begin{tabular}{|l|l|l|l|}
\hline $\begin{array}{l}\text { different lenses } \\
\text { of focal length } \\
(\mathbf{m m})\end{array}$ & $\begin{array}{l}\text { Radial distortion } \\
\text { coefficient }\end{array}$ & \multicolumn{2}{|l|}{ Pixel error } \\
\cline { 2 - 4 } & $\boldsymbol{k}_{\boldsymbol{I}}$ & $\boldsymbol{u}$ & $\boldsymbol{v}$ \\
\hline 30.64 & 0.25901 & 2.04594 & 1.91832 \\
\hline 27.77 & 0.94332 & 3.46324 & 4.13295 \\
\hline 26.31 & 0.52793 & 1.94436 & 2.96566 \\
\hline 21.81 & 0.36694 & 4.43100 & 4.46265 \\
\hline
\end{tabular}


Table 3: Calibration results after optimization using $4^{\text {th }}$ order distortion model for Several Lenses

\begin{tabular}{|c|c|c|c|c|}
\hline \multirow{2}{*}{$\begin{array}{l}\text { different } \\
\text { lenses of } \\
\text { focal } \\
\text { length } \\
(\mathrm{mm})\end{array}$} & \multicolumn{2}{|c|}{$\begin{array}{l}\text { Radial distortion } \\
\text { coefficient }\end{array}$} & \multicolumn{2}{|c|}{ Pixel error } \\
\hline & $k_{1}$ & $k_{2}$ & $u$ & $v$ \\
\hline 30.64 & 0.07210 & $\begin{array}{l}- \\
1.49916\end{array}$ & 1.84158 & 2.07128 \\
\hline 27.77 & 0.94949 & 1.86983 & 3.18991 & 3.97695 \\
\hline 26.31 & 0.56427 & 8.14431 & 2.37465 & 2.23881 \\
\hline 21.81 & 0.37225 & 0.31389 & 4.24701 & 4.44458 \\
\hline
\end{tabular}

The complexity of $2^{\text {nd }}$ order, $4^{\text {th }}$ order and $6^{\text {th }}$ order radial distortion models are tested analytically using different model selection criterions, to choose automatically the best distortion model.

Table 4. Calibration result after optimization using $6^{\text {th }}$ order distortion model for Several Lenses

\begin{tabular}{|c|c|c|c|c|c|}
\hline \multirow{2}{*}{$\begin{array}{l}\text { differen } \\
\text { t } \\
\text { lenses } \\
\text { of focal } \\
\text { length } \\
(\mathbf{m m})\end{array}$} & \multicolumn{3}{|c|}{$\begin{array}{l}\text { Radial distortion } \\
\text { coefficient }\end{array}$} & \multicolumn{2}{|c|}{ Pixel error } \\
\hline & $k_{I}$ & $k_{2}$ & $k_{3}$ & $u$ & $v$ \\
\hline 30.64 & $\begin{array}{l}0.2656 \\
7\end{array}$ & $\begin{array}{l}-12787 \\
0.187\end{array}$ & $\begin{array}{l}0.0442 \\
8\end{array}$ & $\begin{array}{l}1.9329 \\
7\end{array}$ & $\begin{array}{l}1.9052 \\
7\end{array}$ \\
\hline 27.77 & $\begin{array}{l}0.1702 \\
1\end{array}$ & $\begin{array}{l}-09652 \\
0.09\end{array}$ & $\begin{array}{l}0.0297 \\
0\end{array}$ & $\begin{array}{l}2.0263 \\
8\end{array}$ & $\begin{array}{l}2.1845 \\
5\end{array}$ \\
\hline 26.31 & $\begin{array}{l}0.6462 \\
8\end{array}$ & $\begin{array}{l}19.2709 \\
9\end{array}$ & $-\overline{0.0064}$ & $\begin{array}{l}1.9503 \\
8\end{array}$ & $\begin{array}{l}2.4210 \\
6\end{array}$ \\
\hline 21.81 & $\begin{array}{l}0.1376 \\
0\end{array}$ & 0.45825 & $\begin{array}{l}0.0422 \\
1\end{array}$ & $\begin{array}{l}2.4322 \\
1\end{array}$ & $\begin{array}{l}2.3575 \\
2\end{array}$ \\
\hline
\end{tabular}

Table 5. Complexity of four lenses using $2^{\text {nd }}$ order radial distortion model

\begin{tabular}{|l|l|l|l|l|}
\hline $\begin{array}{l}\text { Lenses of } \\
\text { focal length } \\
(\mathbf{m m})\end{array}$ & AIC & BIC & CAIC & MDL \\
\hline 30.64 & 4.839 & 0.936 & 3.936 & -0.112 \\
\hline 27.77 & 8.091 & 4.187 & 7.187 & 3.139 \\
\hline 26.31 & 5.909 & 2.006 & 5.005 & 0.957 \\
\hline 21.81 & 8.879 & 4.975 & 7.975 & 3.927 \\
\hline
\end{tabular}

Table 6. Complexity of four lenses using $4^{\text {th }}$ order radial distortion model

\begin{tabular}{|l|l|l|l|l|}
\hline $\begin{array}{l}\text { Lenses of focal } \\
\text { length }(\mathbf{m m})\end{array}$ & AIC & BIC & CAIC & MDL \\
\hline 30.64 & 4.775 & 0.871 & 3.871 & -0.177 \\
\hline 27.77 & 7.799 & 3.895 & 6.895 & 2.847 \\
\hline 26.31 & 5.597 & 1.694 & 4.694 & 0.646 \\
\hline 21.81 & 8.764 & 4.860 & 7.860 & 3.812 \\
\hline
\end{tabular}

Table 7. Complexity of four lenses using $6^{\text {th }}$ order radial distortion model

\begin{tabular}{|l|l|l|l|l|}
\hline $\begin{array}{l}\text { Lenses of focal } \\
\text { length }(\mathbf{m m})\end{array}$ & AIC & BIC & CAIC & MDL \\
\hline 30.64 & 4.677 & 0.774 & 3.774 & -0.273 \\
\hline 27.77 & 5.141 & 1.238 & 4.238 & 0.190 \\
\hline 26.31 & 5.327 & 1.424 & 4.424 & 0.376 \\
\hline 21.81 & 5.785 & 1.882 & 4.882 & 0.834 \\
\hline
\end{tabular}

MDL is utilized over the other entire criteria in comparing the radial distortion models and picking the best one, which it's a good estimate of the least complex model that will give a model which model the distortion competently. This is compatible with Broaddus opinion in [10], where MDL choose the complexity equal to or less than that of the other criteria without sacrificing a significantly lower error.

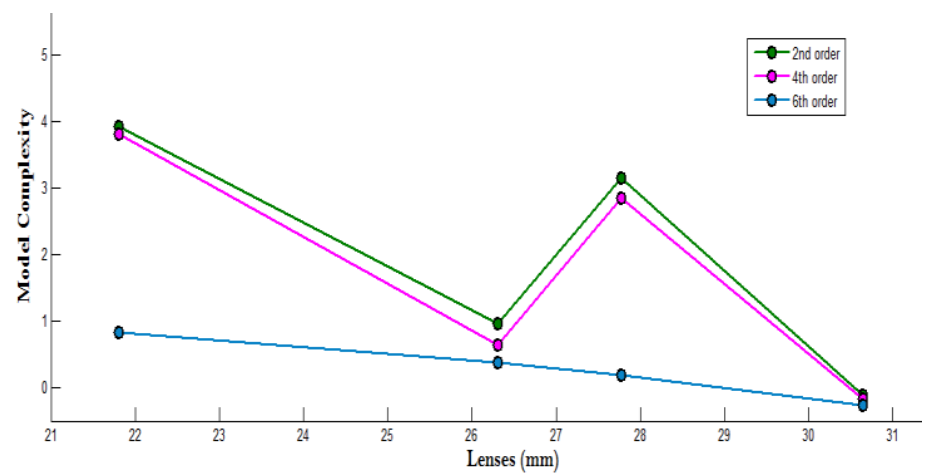

Fig 3. the complexity using MDL criterion of the $2^{\text {nd }}$ and $6^{\text {th }}$ order radial distortion model for four different lenses (1) $30.64 \mathrm{~mm}$, (2) $27.77 \mathrm{~mm}$, (3) $26.31 \mathrm{~mm}$ and (4) $21.81 \mathrm{~mm}$

\section{CONCLUSION}

A complete automatic selection for the camera lens distortion was presented for the use with wide angle camera. Some of information criteria have successful results in choosing the distortion model complexity in automatic way.

Results show that the $6^{\text {th }}$ order radial distortions model it's the best model to use which contain minimum error than $4^{\text {th }}$ and $2^{\text {nd }}$ orders. The model complexity decreases gradually depending on the focal length of the lens, as clarified in figure (3).

\section{REFERENCES}

[1]. J. Heikkila and O. Silven, 1997, A Four-Step Camera Calibration Procedure with Implicit Image Correction," In Proceedings of IEEE Conference on Computer Vision and Pattern Recognition.

[2]. R. Lenz and R. Tsai, 1987, Techniques for Calibration of the Scale Factor and Image Center for High Accuracy 3D Machine Vision Metrology," In Proceedings of the IEEE International Conference on Robotics and Automation, Raleigh NC.

[3]. Tsai, R., 1987, A versatile camera calibration technique for high-accuracy 3D machine vision metrology using off-the-shelf TV cameras and lenses. IEEE Journal on Robotics and Automation.

[4]. El-Melegy MT, Farag AA, 2003, Nonmetric Lens Distortion Calibration: Closed-form Solutions, Robust Estimation and Model Selection, InICCV.

[5]. Abdul, Rihab K. Hamad Sinan M., and Sattar Razi J. Alazawi, 2017, Calibration of Convex Lenses with $2^{\text {nd }}$ 
Order Radial Distortion Model, international journal of computation and applied science.

[6]. Kinoshita, Keisuke, and Michael Lindenbaum, 1999, Camera model selection based on geometric AIC, Computer Vision and Pattern Recognition. Proceedings IEEE Conference.

[7]. Zhang, Zhengyou, 1999, Flexible camera calibration by viewing a plane from unknown orientations, The Proceedings of the Seventh IEEE International Conference.
[8]. Strand R, Hayman E., 2005, Correcting Radial Distortion by Circle Fitting, InBMVC.

[9]. Wang, A., Qiu, T., and Shao, L., 2009, A simple method of radial distortion correction with center of distortion estimation. Journal of Mathematical Imaging and Vision.

[10].Ma, Lili, YangQuan Chen, and Kevin L. Moore, 2004 Rational radial distortion

[11]. Choi, Kai San, Edmund Y. Lam, and Kenneth KY Wong, 2006, Automatic source camera identification using the intrinsic lens radial distortion. Optics express. 